Article

\title{
Energy Efficiency in Greenhouse Evaporative Cooling Techniques: Cooling Boxes versus Cellulose Pads
}

\author{
Antonio Franco ${ }^{1}$, Diego L. Valera ${ }^{2, *}$ and Araceli Peña ${ }^{2}$ \\ 1 ETSIA, University of Sevilla, Ctra. Utrera km 1, 41013 Sevilla, Spain; E-Mail: afranco@us.es \\ 2 Centro de Investigación en Biotecnología Agroalimentaria-BITAL, University of Almería, \\ Ctra. Sacramento s/n, 04120 Almería, Spain; E-Mail: apfernan@ual.es \\ * Author to whom correspondence should be addressed; E-Mail: dvalera@ual.es; \\ Tel.: +34-950-015-546; Fax: +34-950-015-491.
}

Received: 17 December 2013; in revised form: 20 February 2014 / Accepted: 3 March 2014 / Published: 7 March 2014

\begin{abstract}
Evaporative cooling systems using a combination of evaporative pads and extractor fans require greenhouses to be hermetic. The greatest concentration of greenhouses in the world is located in southeast Spain, but these tend not to be hermetic structures and consequently can only rely on fogging systems as evaporative cooling techniques. Evaporative cooling boxes provide an alternative to such systems. Using a low-speed wind tunnel, the present work has compared the performance of this system with four pads of differing geometry and thickness manufactured by two different companies. The results obtained show that the plastic packing in the cooling unit produces a pressure drop of $11.05 \mathrm{~Pa}$ at $2 \mathrm{~m} \cdot \mathrm{s}^{-1}$, which is between $51.27 \%$ and $94.87 \%$ lower than that produced by the cellulose pads. This pressure drop was not influenced by increases in the water flow. The evaporative cooling boxes presented greater saturation efficiency at the same flow, namely $82.63 \%$, as opposed to an average figure of $65 \%$ for the cellulose pads; and also had a lower specific consumption of water, at around $3.05 \mathrm{~L} \cdot \mathrm{h}^{-1} \cdot \mathrm{m}^{-2} \cdot{ }^{\circ} \mathrm{C}^{-1}$. Consequently, we conclude that evaporative cooling boxes are a good option for cooling non-hermetic greenhouses such as those most frequently used in the Mediterranean basin.
\end{abstract}

Keywords: greenhouse; evaporative cooling; pressure drop; heat and mass transfer coefficients; specific water consumption; saturation efficiency 


\section{Nomenclature:}

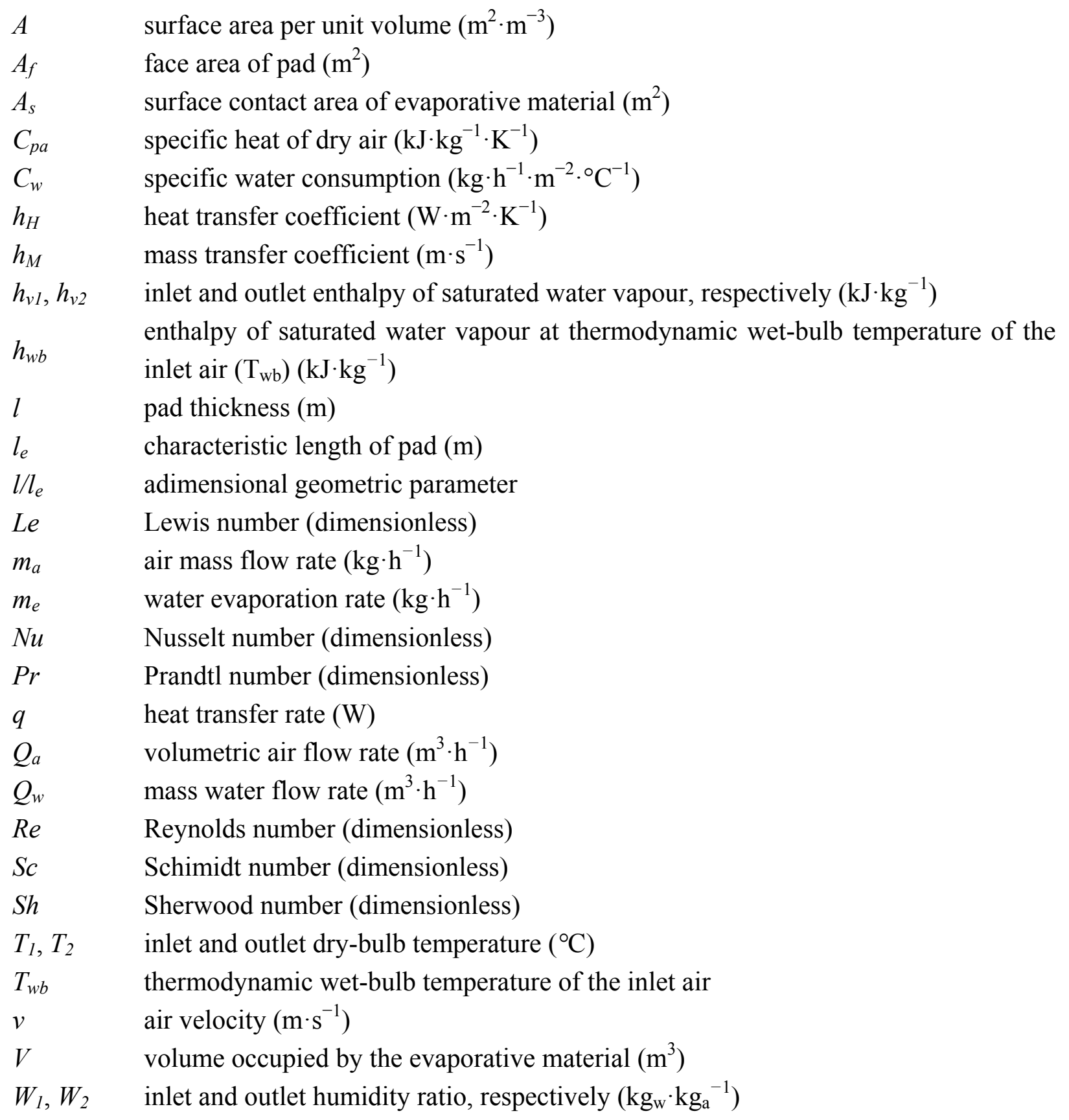

\section{Greek Letters}

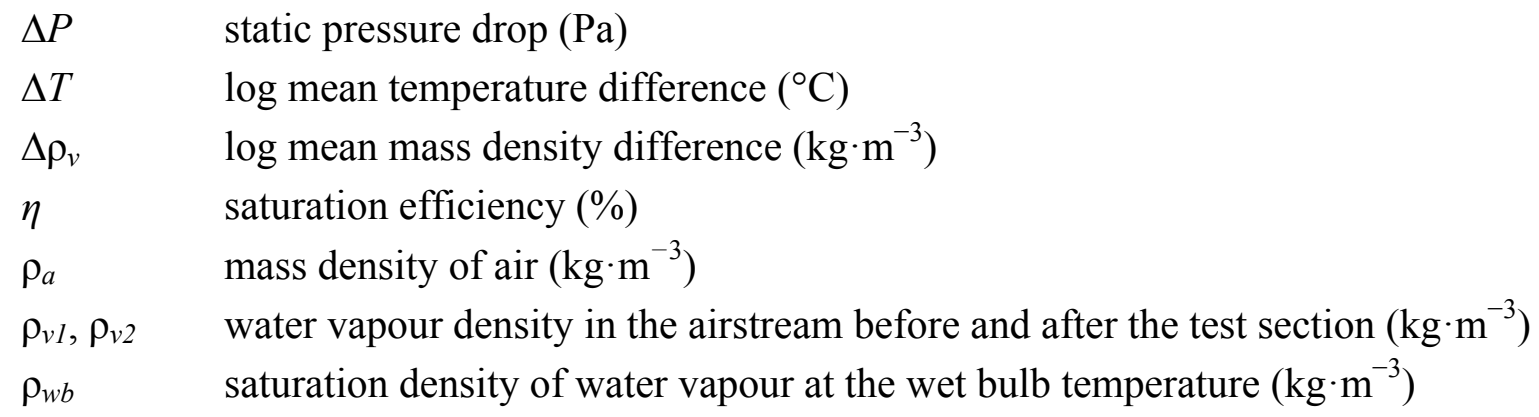




\section{Introduction}

Forced greenhouse crops are an ever more common means of cultivation worldwide. Current estimates put the surface area dedicated to such crops at 700,000 ha, 150,000 of which are located in the Mediterranean basin. Spain is home to 60,000 ha, and approximately half of these are located in the province of Almería.

The greenhouse agrisystem makes a notable contribution to the socio-economic and demographic development of the area in which it is located, and Almería is often cited as the classic example of this model. Over the 2011-2012 season the final production of this sector in Almería accounted for over 1700 million Euros, i.e., $40 \%$ of the province's economic activity, and over $50 \%$ of the total value of exports from the Andalusian region of Spain. At the same time, the sector provides a considerable amount of employment, with over 100,000 workers employed directly in greenhouses on the coast of Almería alone. To a certain extent this has allowed the province to withstand the challenges of the current economic crisis [1].

On the other hand, the greenhouse agrisystem also has major beneficial consequences on the environment. Consumption of $\mathrm{CO}_{2}$ due to the greenhouses is over $10 \mathrm{t} \cdot \mathrm{ha}^{-1} \cdot \mathrm{year}^{-1}$, for instance. In addition, water consumption is four times more efficient than the national average for irrigation.

Over the years this agrisystem has seen the introduction of numerous technological innovations, such as mulching, plasticulture, fertigation, crop protection systems, vegetable crops, phyto-pharmaceuticals, organic production methods and biological pest control, among others. However, one of the current challenges to the sector is the incorporation of climate control techniques as a means of improving both the quality and quantity of the yield, and of allowing year-round production. The main aim is to enhance sustainability in a sector facing increasing competition from abroad, where production costs are often cheaper, in particular labour, which accounts for $40 \%$ of total costs in Almería.

On the other hand, the typically high spring-summer temperatures in the Mediterranean basin make evaporative cooling systems necessary [2]. The evaporative cooling of greenhouses is based on the evaporation of the water in the mass of warm incoming air, thus allowing a decrease in temperature and increase in the humidity content of the air. This can be achieved by directly spraying water inside the greenhouse and combining it with natural ventilation (fog systems), or by obliging the incoming air to pass through dampened evaporative pads and installing fans to ventilate the greenhouse artificially (pad-fan cooling systems) [3].

The air saturation efficiency of the pad-fan system is greater than that of the fog system [4]; it is also cheaper [5] and it consumes less water and energy [6]. However, it requires extremely hermetic greenhouse structures to ensure that all incoming air passes through the evaporative pads along part or the whole of the side wall, with powerful extractor fans being placed along the opposite wall to provide the required suction (Figure 1). The Almería-type greenhouse [7], which accounts for $94.7 \%$ of the greenhouse area in southeast Spain, is not hermetic, and as a result growers have opted for the installation of the fog system, which is better suited to such structures [8]. According to López et al. [6], in a greenhouse equipped with evaporative pads a difference in temperature of up to $11.6{ }^{\circ} \mathrm{C}$ was recorded with respect to a naturally ventilated greenhouse, whereas using the fog system this difference was $10.4{ }^{\circ} \mathrm{C}$. The main drawback of the pad-fan system was the horizontal temperature gradients, with a maximum difference of $11.4{ }^{\circ} \mathrm{C}$ between the pads and the fans. The fog system 
required higher energy consumption $(7.2-8.9 \mathrm{kWh})$ than the pad-fan system $(5.1 \mathrm{kWh})$ for continuous operations over one hour.

Figure 1. Pad-fan evaporative cooling in greenhouse.

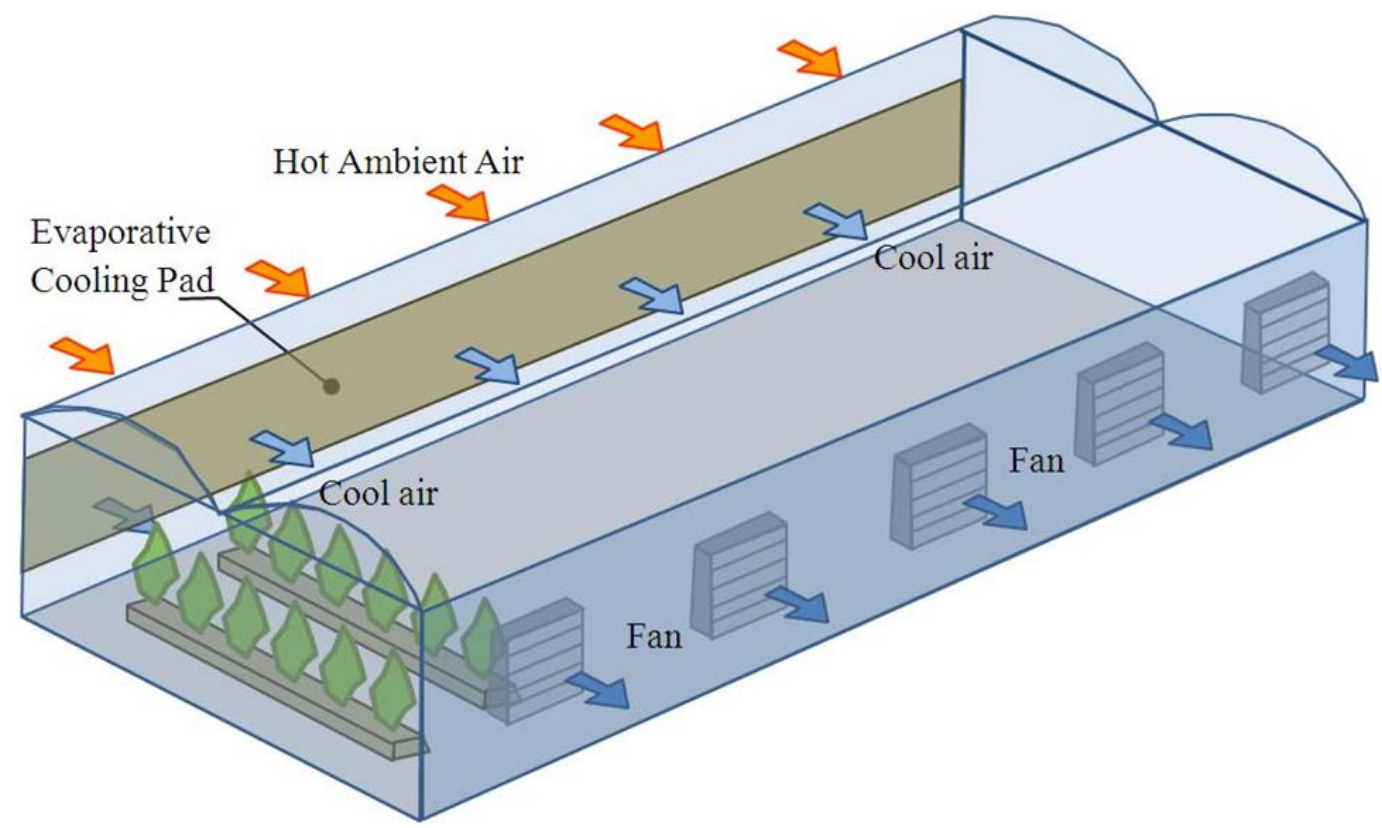

An alternative to the use of the fog system in Almería-type greenhouses would be the use of evaporative cooling boxes (Figure 2). These have been used for some time in industrial installations and consist of an evaporative cooling unit with a cooling chamber, usually equipped with a plastic packing in the form of a honeycomb mesh which allows the air to come into contact with the water. The unit includes a pump for water recycling, as well as a fan which impels the cooled air horizontally into the greenhouse. Consequently, it does not require extremely hermetic structures, since the fan that impels the cool air into the greenhouse is an integral part of the cooling unit. We believe that cooling boxes may provide a viable alternative to fog systems in areas like Almería, where hot, windy weather is common. On such days greenhouse vents must be closed to avoid damage, and as a result the air becomes saturated with water vapour, the fog system fails and there is a risk that the crop may be damaged due to excess humidity. Cooling boxes, however, function correctly irrespective of the outside wind speed. In addition, they do not require such high water quality; osmosis systems frequently need to be installed in areas like southeast Spain to improve water quality when fog systems are employed, in order to avoid obstruction of the nozzles.

The packing material in the cooling chamber is the key element in the heat and mass transfer process, as it fulfills two important functions: it provides a large contact surface for the mixing of the water and air flows, while at the same time ensuring that the transfer process takes as little time as possible [9]. As a result, the amount of water evaporated increases and the temperature of the non-saturated air decreases.

This material usually consists of a plastic grid, though it may also be composed of corrugated cellulose pads, vegetable fibers found locally [10-12], such as wood chips, coconut fibre, etc., or porous inorganic material [13] such as perlite, volcanic rock, etc. These materials are placed in such a 
way as to ensure that they present the maximum possible transfer surface and the minimum resistance to the passage of the airflow.

Figure 2. Evaporative cooling boxes in greenhouse.

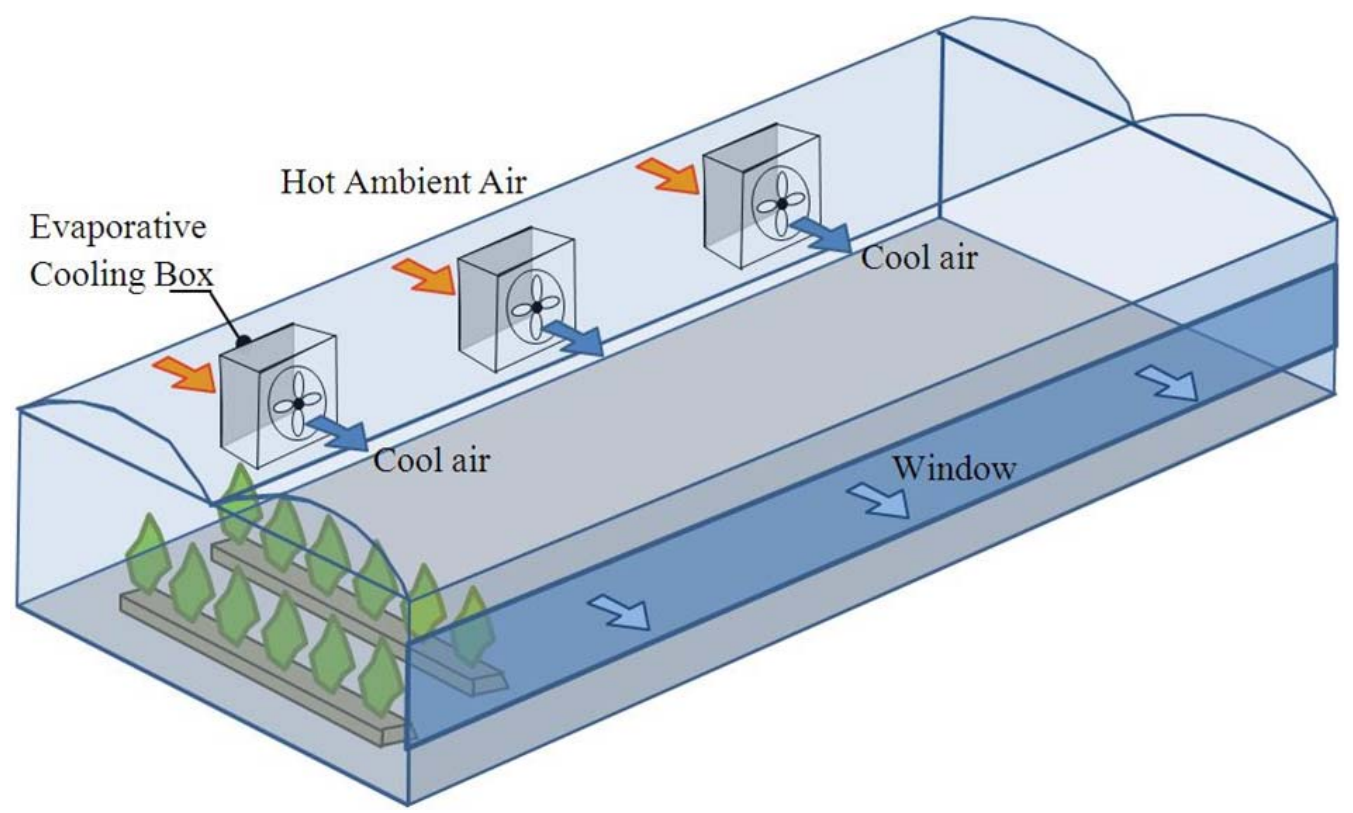

The system also includes a mechanism for the recirculation of water, consisting of a hydraulic pump, pipes situated over the pads and a channel to collect and recycle the drainage water. This direct evaporative cooling technology is still evolving and incorporating a dehumidification system by means liquid desiccant to reduce the humidity of the ambient air and therefore achieve greater reduction in air temperature. This is essential in hot and humid climatic areas where the efficiency of these direct systems is less [14]. Compared to conventional evaporative cooling, the desiccant system lowers average daily maximum temperatures in the hot season by $5.5-7.5{ }^{\circ} \mathrm{C}$, sufficient to maintain viable growing conditions for vegetables crops throughout the year in greenhouses [15].

This evaporative cooling system consumes a greater amount of energy and water than the traditional method of natural ventilation and crop transpiration, thus proving more costly. However, the extra cost can be offset by the increase in earliness, quality and yield, particularly since this system allows production in arid zones during the summer months. Growers are therefore able to extend the campaign, planting sooner and modifying the periods of maximum production.

The aim of the present work, therefore, is to analyze different parameters related to the functioning of an evaporative cooling unit fitted with a plastic grid (high density polyethylene) in a low velocity wind tunnel. The parameters tested are pressure drop, saturation efficiency, heat and mass transfer coefficients and the specific consumption of water at different flow rates of water and air. It is essential to determine these parameters according to the air and water flows used in order to optimize the cooling system's energy efficiency. The pressure drop $(\Delta \mathrm{P})$, for instance, shows the pads' resistance to the passage of air: the greater the pressure drop, the greater the static pressure the fans must produce, and therefore the greater their energy consumption. The saturation efficiency $(\eta)$ indicates the system's capacity to saturate the air, and consequently the capacity to lower the temperature of the air passing through the pad. The heat and mass transfer coefficients $\left(h_{H}\right.$ and $h_{M}$, respectively) help us to determine 
the heat transfered $(\mathrm{q})$ and the water flow evaporated $\left(\mathrm{m}_{\mathrm{e}}\right)$ by the pad. If these parameters are then related with the airflow and geometry of the pad by means of equations, the results can be extrapolated. Finally, the specific water consumption $\left(\mathrm{C}_{\mathrm{w}}\right)$ indicates the evaporative pads' efficiency in water consumption.

The results are compared with those of the corrugated cellulose pads used in the traditional pad-fan cooling system in order to provide recommendations for non-hermetic installations such as Almería-type greenhouses.

\section{Materials and Methods}

\subsection{Evaporative Pads Tested}

The cooling capacity of evaporative pads depends on two factors: the flows of air and water that pass through them and the geometry of the material they are made of. This work analyses the plastic packing used inside an evaporative cooling box on the one hand, and four corrugated cellulose evaporative pads on the other.

The evaporative cooling box is made from high density polyethylene folded by means of thermal welding to form triangular flutes, and it is presented in prefabricated blocks. It consists of two types of 3D mesh. The central mesh consists of straight triangular flutes running perpendicular to the airflow that are moistened by nozzles located inside the cooling box. This central mesh is sandwiched between two pads with flutes that are slanted at an angle of $20^{\circ}$ in order to prevent water droplets from being dragged into the greenhouse (Figure 3).

Figure 3. Characteristics and dimensions of the plastic packing.

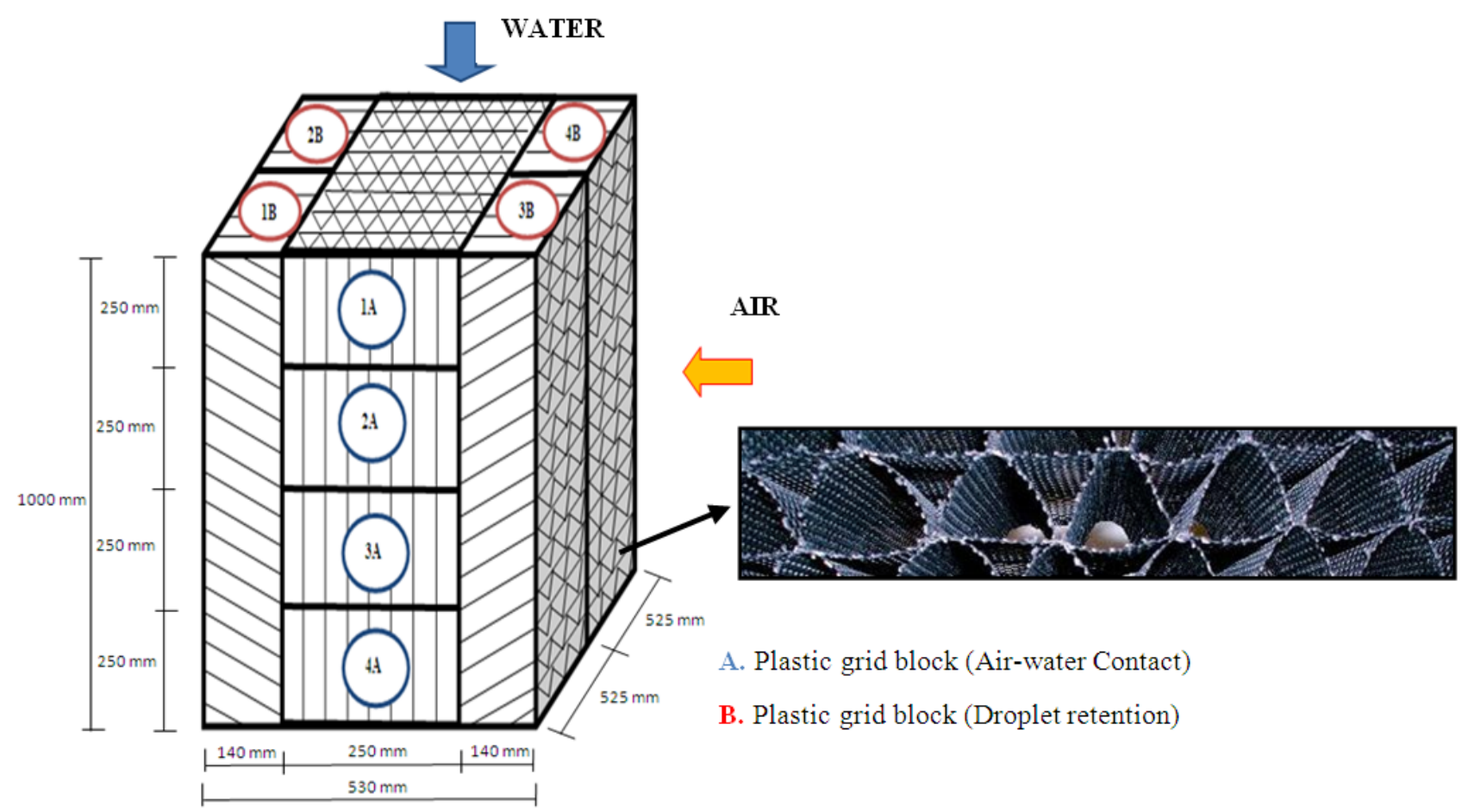

The four corrugated cellulose pads (Figure 4) were manufactured by two different companies. One $100 \mathrm{~mm}$ thick pad was made by the one company (A); this pad presents angles of incidence 
of $45^{\circ}-45^{\circ}$. The remaining three pads were manufactured by another company (B); two of these pads present angles of incidence of $60^{\circ}-30^{\circ}$ and are 50 and $100 \mathrm{~mm}$ thick, while the third shares the same characteristics as the model A one, but with different length and width of undulations.

Figure 4. Close-up of the angles of incidence of the 4 cellulose evaporative pads tested:

(a) $45^{\circ}-45^{\circ} 100 \mathrm{~mm}(\mathrm{~A})$; (b) $45^{\circ}-45^{\circ} 100 \mathrm{~mm}$ (B); (c) $60^{\circ}-30^{\circ} 100 \mathrm{~mm}$; (d) $60^{\circ}-30^{\circ} 50 \mathrm{~mm}$;

(e) a $10 \mathrm{~cm}$ by $60 \mathrm{~cm}$ portion of the $60^{\circ}-30^{\circ} 50 \mathrm{~mm}$.
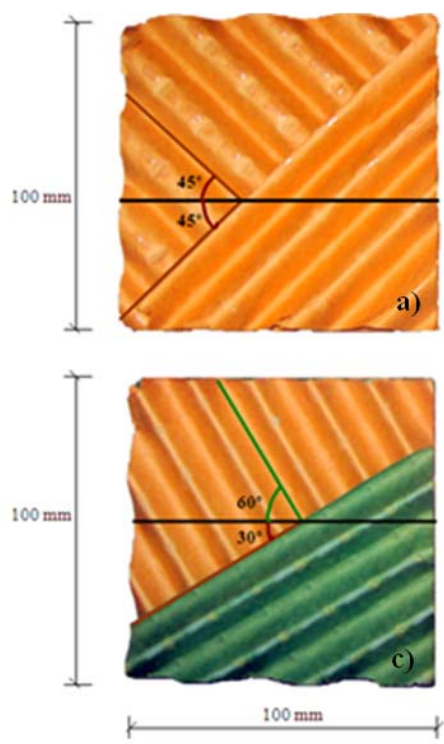
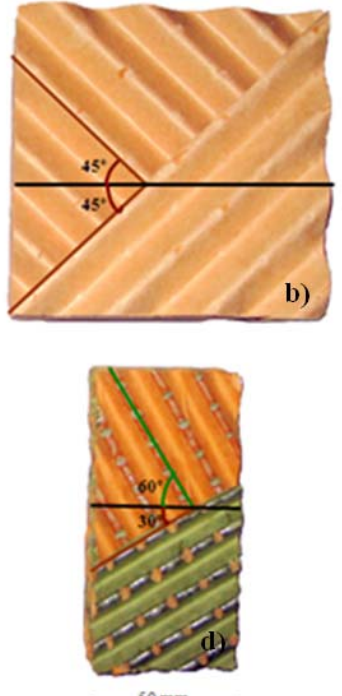

$50 \mathrm{~mm}$

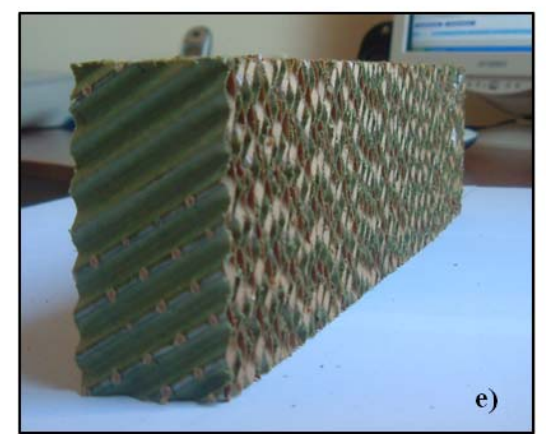

A detailed study was made of the geometric characteristics of the plastic packing tested using three different samples. The following geometric parameters were analysed: angles of incidence of the flutes in the plastic mesh $\left(^{\circ}\right)$, thickness of the grid block $(\mathrm{m})$, base, height and length of the triangular flutes that form the mesh (mm), number of flutes per block (units block ${ }^{-1}$ ) and per unit of contact surface in the block (units $\mathrm{m}^{-2}$ ), specific contact surface of the grid block $\left(\mathrm{m}^{2} \cdot \mathrm{m}^{-3}\right)$, thickness of the plastic $(\mathrm{mm})$, porosity of the grid block $\left(\mathrm{m}^{3} \cdot \mathrm{m}^{-3}\right)$, and adimensional geometric parameter $(l e / l)$ : where le is the characteristic length $(\mathrm{m})$ and $l$ the thickness of the grid block (m). Table 1 provides an overview of these geometric parameters.

Table 1. Summary of the geometric parameters of the plastic packing.

\begin{tabular}{|c|c|c|c|c|c|c|c|c|c|c|}
\hline \multirow[t]{2}{*}{ Type } & \multirow{2}{*}{$\begin{array}{c}\text { Thickness of } \\
\text { grid block } \\
\text { (m) }\end{array}$} & \multirow{2}{*}{$\begin{array}{c}\text { Angles } \\
\left(^{\circ}\right)\end{array}$} & \multirow{2}{*}{$\begin{array}{c}\text { Number of } \\
\text { flutes } \\
\text { (Units/block) }\end{array}$} & \multicolumn{3}{|c|}{$\begin{array}{c}\text { Triangular flutes } \\
\text { (mm) }\end{array}$} & \multirow{2}{*}{$\begin{array}{c}\text { Thicknesof } \\
\text { plastic } \\
\text { (mm) }\end{array}$} & \multirow{2}{*}{$\begin{array}{c}\text { Specific contact } \\
\text { surface } \\
\left(\mathrm{m}^{2} \mathrm{~m}^{-3}\right)\end{array}$} & \multirow{2}{*}{$\begin{array}{c}\text { Dry } \\
\text { porosity } \\
\left(\mathrm{m}^{3} \mathrm{~m}^{-3}\right)\end{array}$} & \multirow[t]{2}{*}{ le/l } \\
\hline & & & & B & $\mathbf{h}$ & $\mathbf{L}$ & & & & \\
\hline Central block & 0.25422 & $90^{\circ}$ & 176 & 50 & 30 & 248 & 1.20 & 51.77 & 0.9690 & 0.07599 \\
\hline Outer pads & 0.14161 & $20^{\circ}$ & 452 & 40 & 27.6 & 148 & 0.84 & 114.93 & 0.9517 & 0.06144 \\
\hline Plastic grip pad & 0.53744 & $20^{\circ}-90^{\circ}-20^{\circ}$ & 2512 & - & - & - & - & 85.14 & 0.9599 & 0.02185 \\
\hline
\end{tabular}

Likewise, the geometric characteristics of the four cellulose pads were also determined and the following parameters were analysed: angles of incidence of the cellulose sheets $\left(^{\circ}\right.$ ), thickness of the pad $(\mathrm{mm})$, length and width of the undulation in the cellulose sheet $(\mathrm{mm})$, number of sheets of each angle per metre width of the pad (units $\mathrm{m}^{-1}$ ), specific contact area (specific area $=$ surface area per unit 
volume) of the pad $\left(\mathrm{m}^{2} \cdot \mathrm{m}^{-3}\right)$, thickness of the sheets $(\mathrm{mm})$, dry porosity of the pad $\left(\mathrm{m}^{3} \cdot \mathrm{m}^{-3}\right)$, adimensional geometric parameter $(l e / l)$ : where $l_{e}$ is the characteristic length $(\mathrm{m})$ and $l$ the thickness of the pad $(\mathrm{m})$. Table 2 provides an overview of these geometric characteristics.

Table 2. Summary of the geometric characteristics of the cellulose pads.

\begin{tabular}{cccccccccc}
\hline Manufacturer & $\begin{array}{c}\text { Thickness } \\
\text { of the pad } \\
(\mathbf{m m})\end{array}$ & $\begin{array}{c}\text { Angles } \\
\left({ }^{\circ}\right)\end{array}$ & $\begin{array}{c}\text { Number of } \\
\text { sheets } \\
(\mathbf{U n i t s} / \mathbf{m})\end{array}$ & $\begin{array}{c}\text { Thickness of } \\
\text { the sheets } \\
(\mathbf{m m})\end{array}$ & $\begin{array}{c}\text { Length of } \\
\text { undulation } \\
(\mathbf{m m})\end{array}$ & $\begin{array}{c}\text { Width of } \\
\text { undulation } \\
(\mathbf{m m})\end{array}$ & $\begin{array}{c}\text { Specific } \\
\text { contact area } \\
\left(\mathbf{m}^{2} \cdot \mathbf{m}^{-3}\right)\end{array}$ & $\begin{array}{c}\text { Dry } \\
\text { le/l }\end{array}$ & $\begin{array}{c}\text { porosity } \\
\left(\mathbf{m}^{3} \cdot \mathbf{m}^{-3}\right)\end{array}$ \\
\hline Company A & 100 & $45^{\circ}-45^{\circ}$ & 157 & $0.213-0.213$ & $19.5-19.5$ & $6.37-6.37$ & 391.114 & 0.02557 & 0.957 \\
Company B & 100 & $45^{\circ}-45^{\circ}$ & 142 & $0.228-0.228$ & $20.5-20.5$ & $7.00-7.00$ & 347.114 & 0.02881 & 0.959 \\
Company B & 100 & $60^{\circ}-30^{\circ}$ & 132 & $0.192-0.191$ & $18.5-17$ & $7.50-7.50$ & 361.516 & 0.02766 & 0.965 \\
Company B & 50 & $60^{\circ}-30^{\circ}$ & 208 & $0.222-0.219$ & $12-11$ & $4.80-4.80$ & 556.752 & 0.03592 & 0.937 \\
\hline
\end{tabular}

\subsection{Experimental Equipment and Procedure}

A low velocity wind tunnel designed and constructed by the Department of Rural Engineering of the University of Almería [16] was adapted to test evaporative pads [17]. This device allows us to control the flows of air and water that pass through the evaporative materials (grid block and pads). A similar test system to that employed in this study to analyze the experimental performance of indirect air-liquid membrane contactors for liquid desiccant cooling systems [18]. The following parameters were registered by the equipment for each value of water and air flow: temperature and relative humidity of the air before and after passing through the materials, speed of passage, pressure drop, water flow applied and the water temperature [19].

Air flow was supplied by a centrifugal fan (HCT-45-2T-3/AL, Sodeca S.A., Sant Quirze de Besora, Spain) with a capacity of $12,800 \mathrm{~m}^{3} \mathrm{~h}^{-1}$ and a diameter of $460 \mathrm{~mm}$, driven by a $2.2 \mathrm{~kW}$ variable-speed three-phase electric motor $(230 \mathrm{~V}$ and $50 \mathrm{~Hz}$ ). An AC inverter (Micromaster 420, Siemens España S.A., Madrid, Spain) was used for speed control, with an output frequency of 0 to $50 \mathrm{~Hz}$ and a setpoint resolution of 0 to $1 \mathrm{~Hz}$. This allowed the fan speed to be decreased from 2865 to $0 \mathrm{rpm}$ by means of a digital microprocessor. The inverter was connected to the computer through a micrologger and digital/analog (D/A) converter that received digital control signals from the personal computer (PC) and sent analog signals to the frequency inverter. Water flow at the entrance was controlled by varying the voltage of the continuous-current hydraulic $12 \mathrm{~V}$ axial pump and readings from the rotameter (flowmeter) with an average range of 3 to $22 \mathrm{~L} \cdot \mathrm{m}^{-1}$ per minute and an error of $\pm 4 \%$.

Air velocity and temperature transmitters (EE70-VT32C5, Elektronik, Engerwitzdort, Austria) were placed $950 \mathrm{~mm}$ upstream from the measurement section and were equipped with a directional hot-film anemometer with a working range of 0 to $10 \mathrm{~m} \cdot \mathrm{s}^{-1}$ and accuracy of $\pm 0.1 \mathrm{~m} \cdot \mathrm{s}^{-1}$ for air velocity measurements.

The static pressure drop through the test section was measured by a differential pressure transducer (SI 727, SI-Special Instruments, Nörlingen, Germany) connected to two Pitot tubes (Airflow Developments, Ltd., Buckinghamshire, U.K.) of $4 \mathrm{~mm}$ diameter, one $450 \mathrm{~mm}$ upstream and one $450 \mathrm{~mm}$ downstream from the middle of the test section. The transducer measurement range was 0 to $200 \mathrm{~Pa}$ with an accuracy of $\pm 0.25 \%$ full scale (f.s.), hysteresis and reproducibility of $\pm 0.1 \%$ f.s., and 
temperature error of $\pm 0.025 \%$ per ${ }^{\circ} \mathrm{C}$, and a 0 to $10 \mathrm{~V}$ signal output. The real-time readings were stored on the hard disk of a personal computer via the data acquisition unit.

The temperature and humidity of the air current were measured using six digital relative humidity/temperature sensors (SHT75 series, Sensirion, Zurich, Switzerland) with 9-bit digital output and an accuracy of $\pm 1.8 \%$ for relative humidity and $\pm 0.3{ }^{\circ} \mathrm{C}$ for temperature. These sensors do not require calibration. The sensors were located in groups of three, $700 \mathrm{~mm}$ upstream and downstream from the sample to be tested. They were mounted on two rods placed across the width of the test section (Figure 5). Data were obtained on the humidity and temperature of the air flow both before and after it passed through the evaporative pad.

Figure 5. Frame for testing evaporative materials: (a) plastic grid block; (b) cellulose pads.
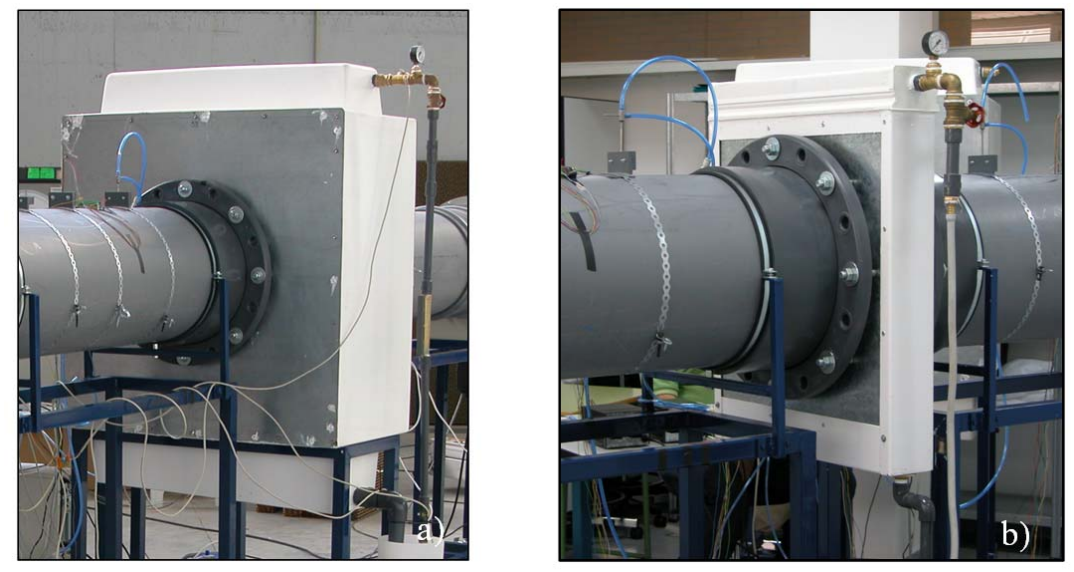

The temperature of the water in the recirculation circuit was measured at three different points: at the entrance to and exit from the pad, and in the recirculation tank. For this purpose, we used digital thermometers (DS18S20, Maxim Integrated Products, Sunnyvale, CA, USA) that provided 9-bit temperature measurements. These sensors communicated over a bus that required only one data line (and ground) for communication with a central microprocessor. Their operational temperature range was $-55^{\circ} \mathrm{C}$ to $+125{ }^{\circ} \mathrm{C}$, with an accuracy of $\pm 0.5{ }^{\circ} \mathrm{C}$ over the range of $-10{ }^{\circ} \mathrm{C}$ to $+85^{\circ} \mathrm{C}$. To calculate the mass flow of evaporated water $\left(\mathrm{kg} \mathrm{h}^{-1}\right.$ per $\mathrm{m}^{2}$ of pad area), we used a scale that measured the weight of the water in the recirculation tank. For this purpose we used a CTC load cell of $50 \mathrm{~N}$ capacity, specially designed to work in traction and compression, with gauges to measure shear strain, and a VMA-10 signal conditioner (both from Dinacell Electrónica, Madrid, Spain).

The signals that the sensors emitted were recorded by means of an electric circuit designed ad hoc with eight analog inputs with a resolution of $10 \mathrm{bits}$, six digital inputs for the humidity/temperature sensors, and an input for the three temperature probes controlled by a bus. The flow of control and data was managed by an RS-232C connection to a PC.

A frame was constructed to connect the evaporative materials to the wind tunnel, and this was also adapted to fit the plastic grid block, as Figure 5 shows. The frame for the plastic grid block is an adaptation provided by the manufacturer. Made of polyester reinforced with fiber glass, its cross section measures $1 \mathrm{~m} \times 1 \mathrm{~m}$ and the filling consisted of four blocks of the central mesh and four blocks of the outer mesh, making a total thickness of $54 \mathrm{~cm}$ (Figure 3). In the upper part, PVC piping supplies water through four nozzles to moisten the pad. In the lower part there is a drainage device. To adapt the 
pad to the section of the wind tunnel a $100 \mathrm{~cm} \times 100 \mathrm{~cm}$ galvanised steel sheet with a central orifice of $38.8 \mathrm{~cm}$ diameter was placed over the front and back surfaces. This was attached using 8 screws of $10 \mathrm{~mm}$ diameter on each side which fitted to the flanges of the wind tunnel.

The frame used for testing the corrugated cellulose pads measured $62.5 \mathrm{~cm}$ wide by $12.5 \mathrm{~cm}$ thick and $84 \mathrm{~cm}$ high. The system of water distribution was located in the upper part, consisting of a $20 \mathrm{~mm}$ diameter PVC pipe with $2 \mathrm{~mm}$ holes $65 \mathrm{~mm}$ apart. As in the frame for the plastic grid block, the test section is circular with a diameter of $38.8 \mathrm{~cm}$, coinciding with the inside diameter of the wind tunnel, and the drainage system is located in the lower part.

The experimental procedure was the same for both types of evaporative cooling materials: the plastic grid block and the cellulose pads. Three different samples of each type of pad were used. All materials were submerged in water for $24 \mathrm{~h}$ prior to each experiment to ensure that they were totally moistened in the case of the plastic pad and saturated in the case of the cellulose pads.

For the cellulose pads, four different water flows were tested. These were both below and above the minimum $6.2 \mathrm{~L} \cdot \mathrm{min}^{-1} \cdot \mathrm{m}^{-1}$ recommended by ASABE [20] for vertical corrugated cellulose pads of $100 \mathrm{~mm}$ thickness. The flows $\left(\mathrm{Q}_{\mathrm{w}}\right)$ for each replication were: 5, 6.6, 8.3 and $10 \mathrm{~L} \cdot \mathrm{min}^{-1}$ per linear metre of pad mounted vertically, and when expressed as flow per unit of contact surface $\left(\mathrm{m}^{2}\right)$ of the pad they become $0.128,0.171,0.214$ and $0.256 \mathrm{~L} \cdot \mathrm{s}^{-1} \cdot \mathrm{m}^{-2}$, respectively.

For the plastic grid block, three different water flows were tested: $10.25,12.85$ and $15.35 \mathrm{~L} \cdot \mathrm{min}^{-1}$ per linear metre of pad mounted vertically, which is equivalent to $0.171,0.214$ and $0.256 \mathrm{~L} \cdot \mathrm{s}^{-1} \cdot \mathrm{m}^{-2}$, respectively, when expressed as flow per unit of contact surface $\left(\mathrm{m}^{2}\right)$. As these are identical to the last three flow rates tested for the cellulose pads, meaningful comparisons can be made regarding their functioning.

The tests began with a fixed flow of water. After $10 \mathrm{~min}$ the fan was started at an initial velocity of $0.3 \mathrm{~m} \cdot \mathrm{s}^{-1}$, increasing up to $4 \mathrm{~m} \cdot \mathrm{s}^{-1}$ in six steps and then decreasing once again to the initial velocity in order to check for possible errors of hysteresis in the sensors. Hysteresis is a phenomenon that produces measurement errors, since the sensor's output signal depends on its previous state. In order to avoid this effect, all sensors have measured the analyzed parameters for increasing airflows, and later for decreasing ones. Each increase and decrease in airflow is therefore approximately $0.6 \mathrm{~m} \cdot \mathrm{s}^{-1}$, and after each variation the material was allowed a 5-min interval in which to readapt to the new conditions of air and water flow before measurements were taken. At each air velocity 100 data were recorded at approximately 3 -s intervals by each of the sensors used.

\subsection{Mathematical Model}

Considering the evaporative material as a moistened porous medium through which flows of air and water pass, the following expressions were used to characterize their functioning based on energy and water balance between the current of air and the moistened porous medium. From these equations we obtained adimensional correlations of the heat and mass transfer coefficients of the corrugated cellulose evaporative pads using energy and matter balances [21]. These were also obtained for the thin and thick PVC sponge pads [22]:

$$
q=m_{\mathrm{a}} C_{\mathrm{pa}}\left(T_{1}-T_{2}\right)+m_{\mathrm{a}}\left[W_{1}\left(h_{\mathrm{v} 1}-h_{\mathrm{wb}}\right)-W_{2}\left(h_{\mathrm{v} 2}-h_{\mathrm{wb}}\right)\right]
$$




$$
m_{e}=m_{a}\left(W_{2}-W_{1}\right)
$$

where $q$ is the flow of transferred heat (W) and $m_{e}$ the flow of evaporated water $\left(\mathrm{kg} \cdot \mathrm{h}^{-1}\right) ; C_{p a}$ the specific heat of dry air $\left(\mathrm{kJ} \cdot \mathrm{kg}^{-1} \cdot \mathrm{K}^{-1}\right) ; T_{1}$ the dry temperature of the incoming air $\left({ }^{\circ} \mathrm{C}\right) ; T_{2}$ the dry temperature of the outgoing air $\left({ }^{\circ} \mathrm{C}\right) ; h_{v 1}$ and $h_{v 2}$ the enthalpy of saturated water vapour at the entrance and exit of the pad, respectively $\left(\mathrm{kJ} \cdot \mathrm{kg}^{-1}\right) ; h_{w b}$ the enthalpy of saturated water vapour at the wet bulb temperature of the incoming air $\left(T_{w b}\right)\left(\mathrm{kJ} \cdot \mathrm{kg}^{-1}\right) ; m_{a}$ the mass flow of incoming air $\left(\mathrm{kg} \cdot \mathrm{h}^{-1}\right)$ which can be expressed as $m_{a}=\rho_{a} \cdot Q_{a}$, where $\rho_{a}$ is the density of the air $\left(\mathrm{kg} \cdot \mathrm{m}^{-3}\right)$ and $Q_{a}$ is the airflow through the pad $\left(\mathrm{m}^{3} \cdot \mathrm{h}^{-1}\right) ; W_{1}$ and $W_{2}$ are the absolute humidity of the air on entering and leaving the pad, respectively $\left(\mathrm{kg}_{\mathrm{w}} \cdot \mathrm{kg}_{\mathrm{a}}{ }^{-1}\right)$.

An alternative way of expressing the flow of transferred heat $(q)$ and the flow of evaporated water $\left(m_{e}\right)$, respectively, is to use the product of the heat transfer coefficient and the mean logarithmic difference in temperature $(\Delta T)$, and the product of the mass transfer coefficient and the mean logarithmic difference in the water vapour density $\left(\Delta \rho_{v}\right)$, in $\mathrm{kg} \mathrm{m}^{-3}$. This will allow us to express Equations (1) and (2) as:

$$
\begin{gathered}
q=h_{\mathrm{H}} A_{\mathrm{S}} \Delta T \\
m_{\mathrm{e}}=h_{\mathrm{M}} A_{\mathrm{S}} \Delta \rho_{\mathrm{v}}
\end{gathered}
$$

where $h_{H}$ is the coefficient of heat transfer $\left(\mathrm{W} \mathrm{m}{ }^{-2} \mathrm{~K}^{-1}\right), h_{M}$ the coefficient of mass transfer $\left(\mathrm{m} \cdot \mathrm{s}^{-1}\right)$, $A_{s}$ contact surface area of the material $\left(\mathrm{m}^{2}\right)$. The mean logarithmic difference in temperature $(\Delta \mathrm{T})$ and water vapour density $\left(\Delta \rho_{v}\right)$, respectively, can be expressed as:

$$
\begin{gathered}
\Delta T=\frac{\left(T_{2}-T_{1}\right)}{\ln \left(\left(T_{2}-T_{\mathrm{wb}}\right) /\left(T_{1}-T_{\mathrm{wb}}\right)\right)} \\
\Delta \rho_{\mathrm{v}}=\frac{\left(\rho_{\mathrm{v} 2}-\rho_{\mathrm{v} 1}\right)}{\ln \left(\left(\rho_{\mathrm{v} 1}-\rho_{\mathrm{wb}}\right) /\left(\rho_{\mathrm{v} 2}-\rho_{\mathrm{wb}}\right)\right)}
\end{gathered}
$$

where $\rho_{v 1}$ and $\rho_{v 2}$ are the water vapour density on entering and leaving the tested materials, respectively $\left(\mathrm{kg} \cdot \mathrm{m}^{-3}\right)$, and $\rho_{w b}$ is the saturated water vapour density at the wet bulb temperature $\left(\mathrm{kg} \cdot \mathrm{m}^{-3}\right)$.

The correlations of Hilpert [23] correlate heat and mass transfer by forced convection in external cross flows through a circular surface similar to that of the materials tested, where the Nusselt number $(\mathrm{Nu})$ correlates with the Reynolds $(\mathrm{Re})$ and Prandtl (Pr) numbers, and the Sherwood number $(\mathrm{Sh})$ correlates with the Reynolds $(R e)$ and Schimidt $(S c)$ numbers, as in the following expressions:

$$
\begin{aligned}
& N_{\mathrm{u}}=C_{1} R_{\mathrm{e}}{ }^{\mathrm{m} 1} P_{\mathrm{r}}^{1 / 3} \\
& S_{\mathrm{h}}=C_{2} R_{\mathrm{e}}{ }^{\mathrm{m} 2} S_{\mathrm{c}}{ }^{1 / 3}
\end{aligned}
$$

where $C_{1}, C_{2}, m_{1}$ and $m_{2}$ are constants for the different geometries of the evaporative materials and for the different air and water flows passing through them, which can be obtained as a linear relationship between $\left(\mathrm{Nu} \mathrm{Pr}{ }^{-1 / 3}\right) v s$. $\mathrm{Re}$, and $\left(\mathrm{Sh} \mathrm{Sc}^{-1 / 3}\right) v s . \mathrm{Re}$, respectively.

It proves interesting to add an adimensional geometric parameter to the two previous expressions. This characteristic parameter may be the ratio between the characteristic length $\left(l_{e}\right)$ and thickness of the pad $(l)$ elevated to a power, following the examples of similar research works $[20,21]$. 
In the present study the adimensional Hilpert correlations will be obtained by means of a least squares fit, introducing the adimensional geometric parameter $\left(l_{e} / l\right)$ but using four evaporative pads of different geometry and thickness, as well as the plastic grid block.

The saturation efficiency $(\eta)$ is another important expression used to characterise the air saturation capacity of the evaporative pads. This is defined as the ratio between the thermal difference on passing through the pad $\left(T_{1}-T_{2}\right)$ and the maximum thermal difference that would occur if the air were saturated $\left(T_{1}-T_{\mathrm{wb}}\right)$ :

$$
\eta=\frac{\left(T_{1}-T_{2}\right)}{\left(T_{1}-T_{\mathrm{wb}}\right)}
$$

Finally, we can also express the specific water consumption $\left(C_{w}\right)$ of the materials $\left(\mathrm{kg} \cdot \mathrm{h}^{-1} \cdot \mathrm{m}^{-2} \cdot{ }^{\circ} \mathrm{C}^{-1}\right)$, expressed as the mass flow of evaporated water per unit of exposed surface $\left(A_{f}\right)$ and the thermal difference that can be achieved for given air conditions on entering the materials:

$$
C_{\mathrm{w}}=\frac{m_{\mathrm{e}}}{\left(T_{1}-T_{2}\right) A_{\mathrm{f}}}
$$

Substituting Equation (9) in Equation (10) the water consumption of the material depends on the air velocity on passing through it, the material's saturation efficiency and the air conditions on entering, or:

$$
C_{\mathrm{w}}=\frac{m_{\mathrm{e}}}{\eta\left(T_{1}-T_{\mathrm{wb}}\right) A_{\mathrm{f}}}
$$

\section{Results and Discussion}

\subsection{Pressure Drop}

Comparison of the pressure drop of the five evaporative materials studied for the different water and air flows (Figure 6) reveals that the same sequence is repeated for water flows of $0,0.171,0.214$ and $0.256 \mathrm{~L} \cdot \mathrm{s}^{-1} \cdot \mathrm{m}^{-2}$. The plastic grid block produces a lower pressure drop than any of the cellulose pads tested. Among the latter the lowest and highest pressure drops are produced by the $45^{\circ}-45^{\circ}$ $100 \mathrm{~mm}$ (B pad) and the $45^{\circ}-45^{\circ} 100 \mathrm{~mm}$ (A pad), respectively.

When the pads are dry, the mean increase in the pressure drop of the cellulose pads as opposed to the plastic block is between $51.27 \%$ for the $45^{\circ}-45^{\circ} 100 \mathrm{~mm} \mathrm{~B}$ pad and $94.87 \%$ for the $45^{\circ}-45^{\circ}$ $100 \mathrm{~mm}$ A pad.

The results show that in all four cellulose pads tested, the pressure drop increased with the air speed and water flow applied. It is known that the pressure drop produced on the passing of air through the pad is directly proportional to the square of the air speed. On the other hand, the increase in the water flow applied at the upper part of the pad also produces an increase in the pressure drop. This is due to the reduction in the pad's porosity $\left(\mathrm{m}^{3} \cdot \mathrm{m}^{-3}\right)$, as the increase in water flow means that more water is in contact with the pad, and therefore the volume of air passing through the pad decreases. 
Figure 6. Comparison of pressure drop between the cellulose pads and the plastic grid block at different air velocities and for the following water flows: (a) dry; (b) $0.171 \mathrm{~L} \cdot \mathrm{s}^{-1} \cdot \mathrm{m}^{-2}$; (c) $0.214 \mathrm{~L} \cdot \mathrm{s}^{-1} \cdot \mathrm{m}^{-2}$; (d) $0.256 \mathrm{~L} \cdot \mathrm{s}^{-1} \cdot \mathrm{m}^{-2}$.

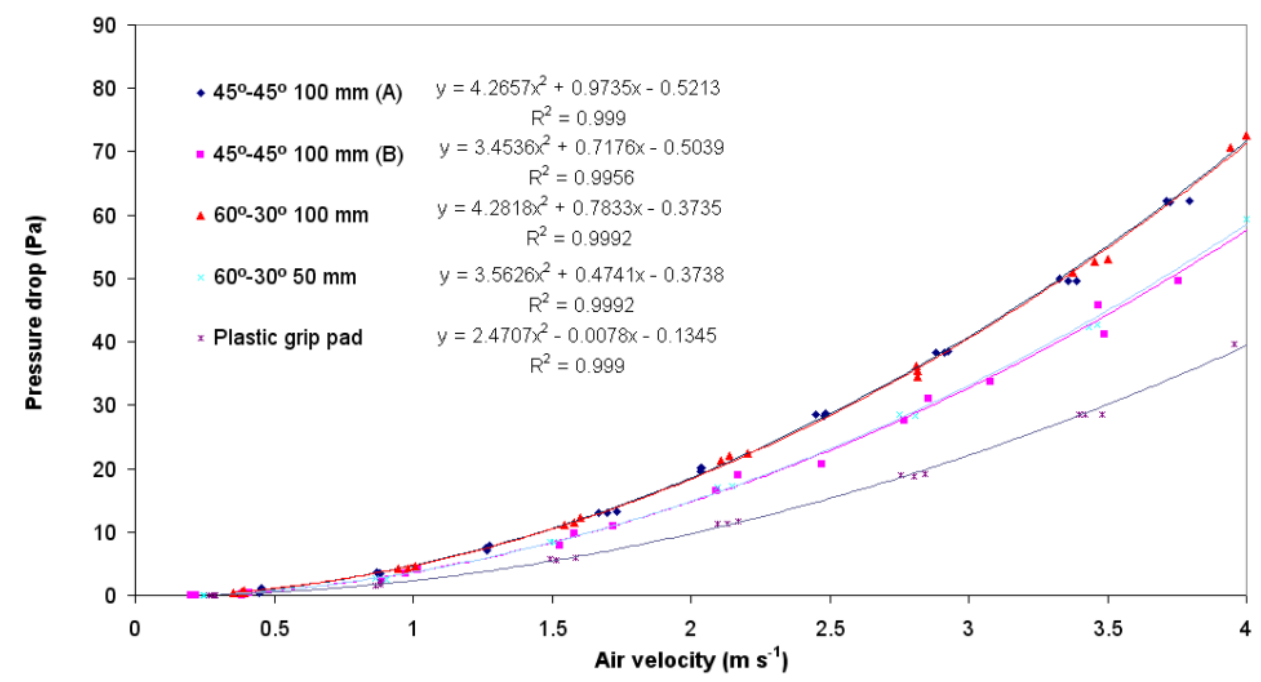

(a)

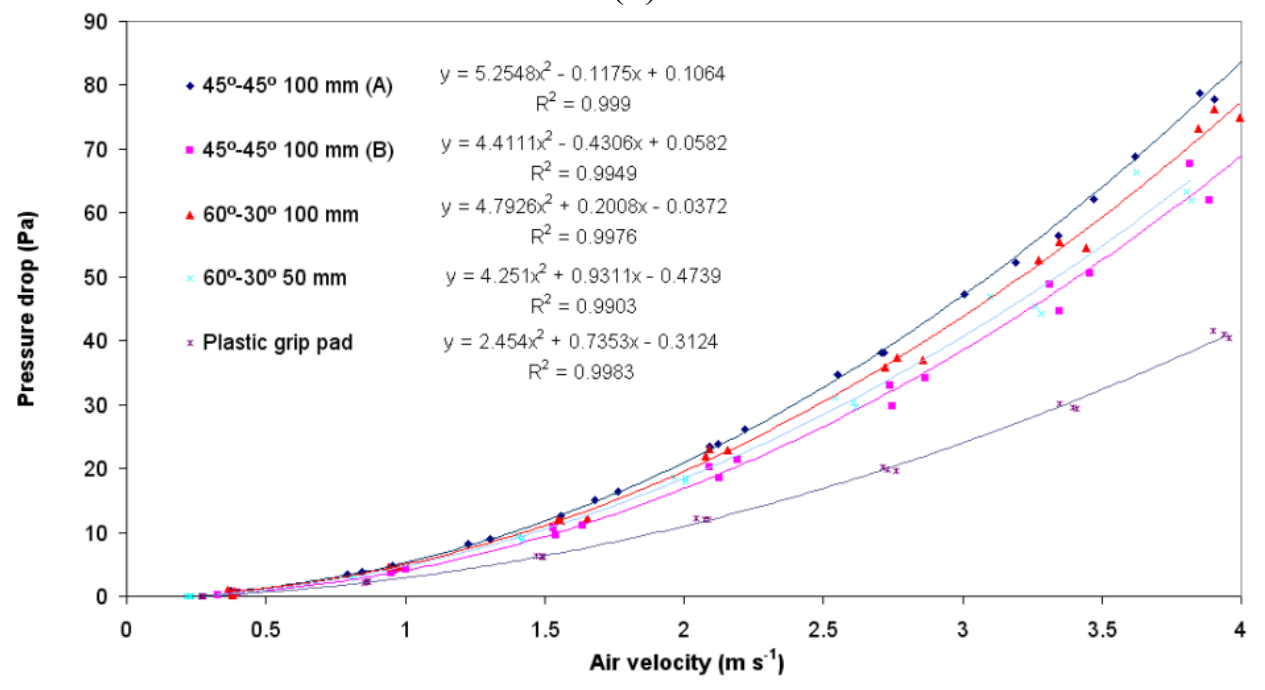

(c)

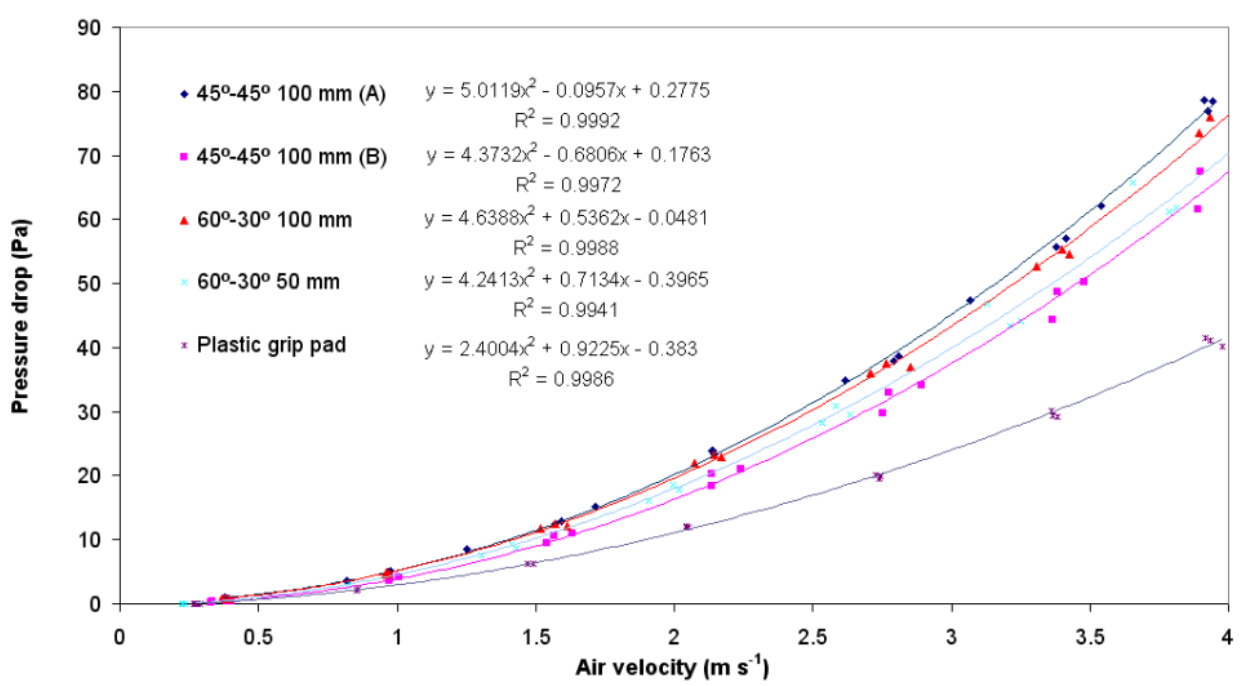

(b)

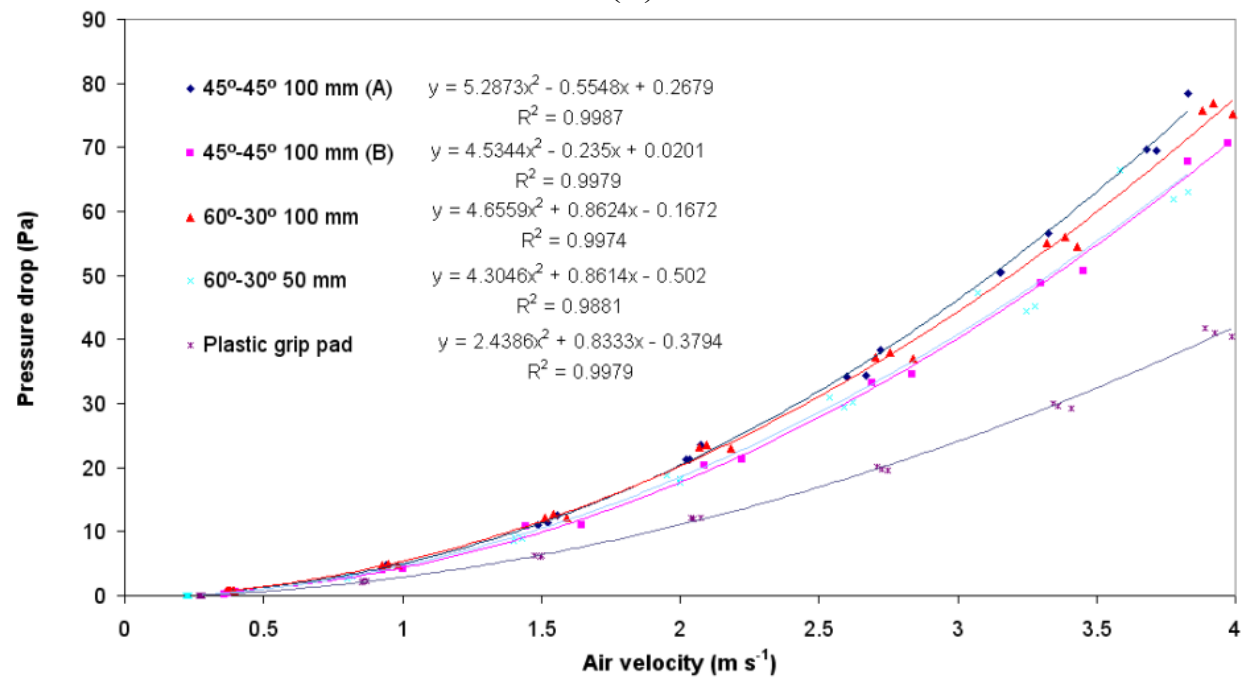

(d) 
As commented above, when the pads are moistened the water flow increases the pressure drop for the cellulose pads, but this increase is negligible in the case of the plastic grid pad. It follows that the greater the water flow, the greater the difference in pressure drop between the plastic pad and the cellulose ones.

\subsection{Air Saturation Efficiency}

Figure 7 compares the air saturation efficiency of the five evaporative pads tested at different air and water flows. It can be seen that the saturation efficiency of the plastic grip block is far greater than that of any of the four cellulose pads. Among the latter, the most and least efficient in this respect are the $45^{\circ}-45^{\circ} 100 \mathrm{~mm}$ (A pad) and the $60^{\circ}-30^{\circ} 50 \mathrm{~mm}$ pad, respectively.

It is noteworthy that in the cellulose pads the highest values of efficiency are produced at low velocities, decreasing as the air velocity increases. However, in the case of the plastic grid block the highest values of efficiency occur at air velocities close to $2 \mathrm{~m} \cdot \mathrm{s}^{-1}$, falling slightly as velocities increase to $4 \mathrm{~m} \cdot \mathrm{s}^{-1}$. Compared to the cellulose pads, the plastic grid block therefore presents the advantage of allowing a greater airflow to pass through the pad while at the same time producing a greater thermal difference.

The mean difference in the saturation efficiency of the plastic grid block and that of the most efficient cellulose pad $\left(45^{\circ}-45^{\circ} 100 \mathrm{~mm}, \mathrm{~A}\right)$ is 15.74 points, i.e., a mean increase of $24.62 \%$. Compared to the least efficient pad $\left(60^{\circ}-30^{\circ} 50 \mathrm{~mm}\right)$ this difference is 19.09 points, i.e., a mean increase of $31.78 \%$.

Figure 7. Comparison of the air saturation efficiency of the cellulose pads and the plastic grid pad at different air velocities and water flows.

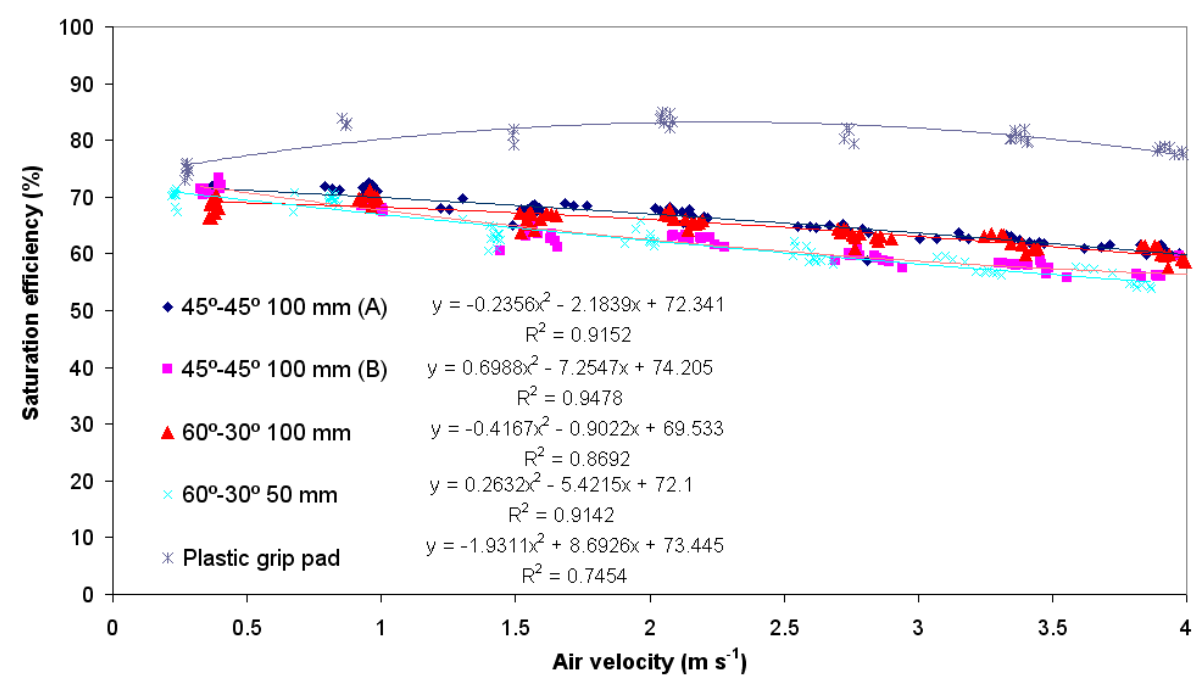

As the air speed increases, the length of time that the air comes into contact with the water decreases, as does the saturation of the air, and consequently the saturation efficiency is lower. This also occurs with the specific surface of the pad $\left(\mathrm{m}^{2} \cdot \mathrm{m}^{-3}\right)$; the lower the specific surface $\left(A_{\mathrm{e}}\right)$, the lower the contact between water and air, and therefore the lower the air saturation efficiency. On the other hand, the saturation efficiency remains constant despite variations in the water flow applied to the pad [17]. 


\subsection{Coefficients of Heat and Mass Transfer}

Comparison of the heat and mass transfer coefficients reveals significant differences between the evaporative pads studied. Calculation of the heat and mass transfer coefficients for the four models of cellulose evaporative pads, considering several water and air flows, allows us to analyze their effects on transfer processes.

The plastic grid block produced a higher heat transfer coefficient than any of the cellulose pads at air velocities of over $1.5 \mathrm{~m} \cdot \mathrm{s}^{-1}$ (Figure 8). Of the cellulose pads, the lowest and highest heat transfer coefficients corresponded to the $45^{\circ}-45^{\circ} 100 \mathrm{~mm}(\mathrm{~B} \mathrm{pad})$ and the $60^{\circ}-30^{\circ} 50 \mathrm{~mm}$ pad, respectively. In fact the latter produced an even higher coefficient that the plastic grid blocks at air velocities of below $1.5 \mathrm{~m} \cdot \mathrm{s}^{-1}$.

Figure 8. Comparison of the heat transfer coefficients of the cellulose pads and the plastic grid block at different air velocities and water flows.

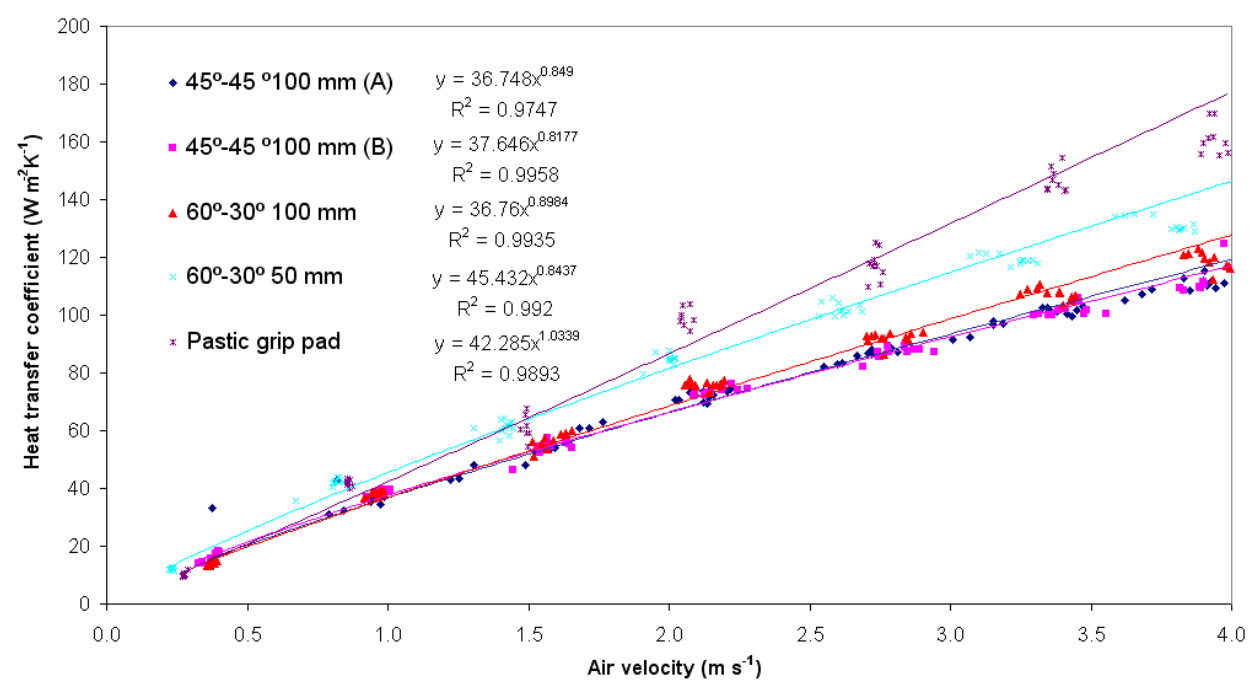

Figure 9 shows that the $60^{\circ}-30^{\circ} 50 \mathrm{~mm}$ pad presents the highest mass transfer coefficient, probably due to the fact that it also presents the highest contact surface; and Figure 10 shows the uncalibrated non-dimensional correlations of heat and mass transfer of all the evaporative materials tested. By introducing an adimensional geometric parameter related to the thickness and specific area of the materials in the uncalibrated non-dimensional correlations shown in Equations (7) and (8), we obtain the calibrated adimensional correlations of heat and mass transfer, as shown in Figure 11.

The correlations that include the adimensional geometric parameters of the pads were obtained by means of a least squares fit and are expressed as follows:

$$
\begin{gathered}
N_{\mathrm{u}}=0.091\left(\frac{l_{\mathrm{e}}}{l}\right)^{0.32} R_{e}^{0.975} P_{r}^{1 / 3} \\
R^{2}=0.9723 \\
S_{\mathrm{h}}=0.036\left(\frac{l_{\mathrm{e}}}{l}\right)^{0.32} R_{\mathrm{e}}^{0.975} S_{\mathrm{c}}^{1 / 3} \\
R^{2}=0.9280
\end{gathered}
$$


Figure 9. Comparison of the mass transfer coefficients of the cellulose pads and the plastic grid block at different air velocities and water flows.

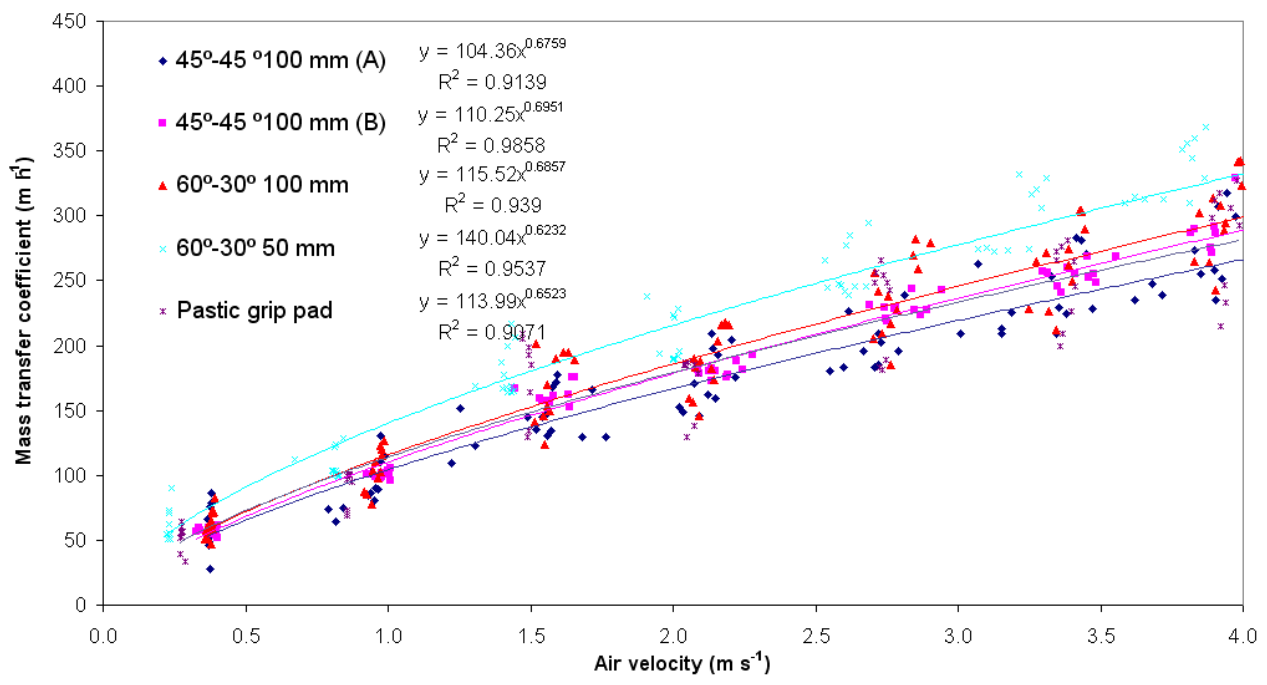

Figure 10. Uncalibrated non-dimensional correlations of (a) heat transfer coefficients and (b) mass transfer coefficients of all tested materials.

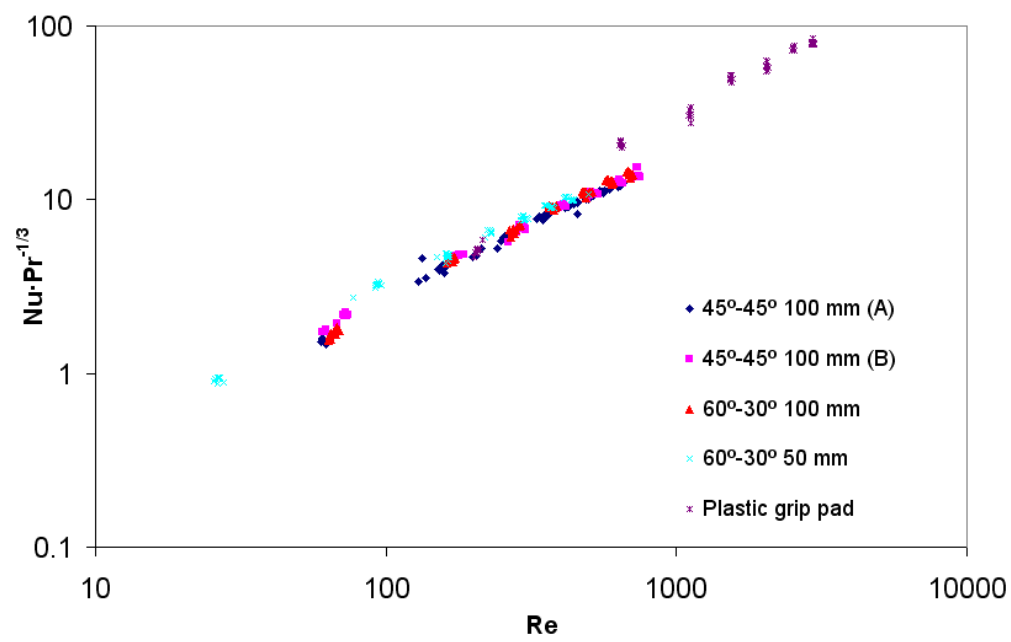

(a)

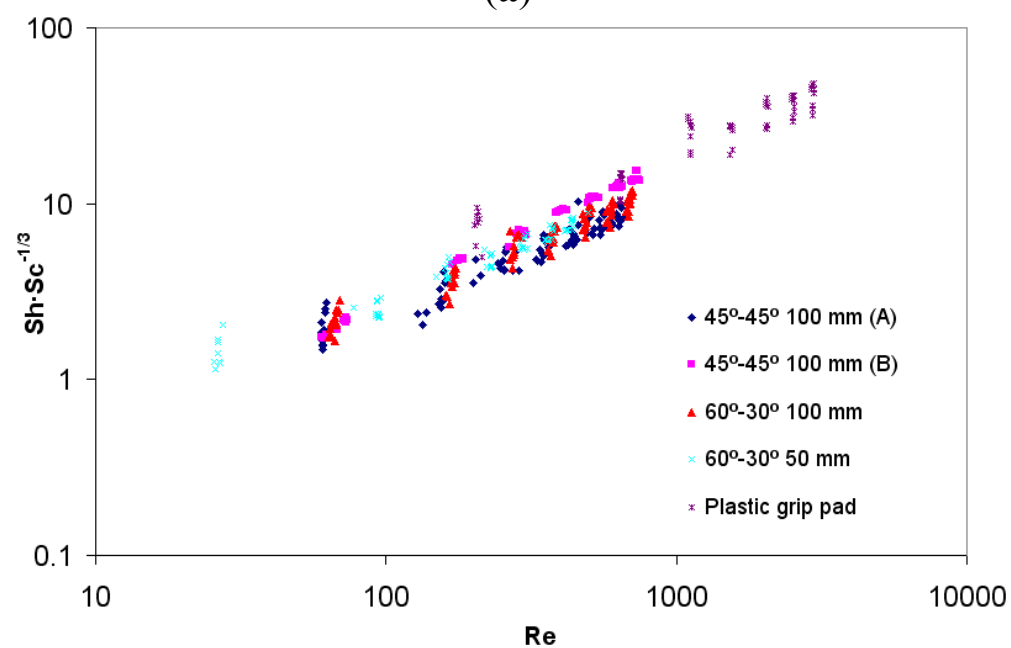

(b) 
Figure 11. Calibrated non-dimensional correlations of (a) heat transfer coefficients and (b) mass transfer coefficients of all tested materials.

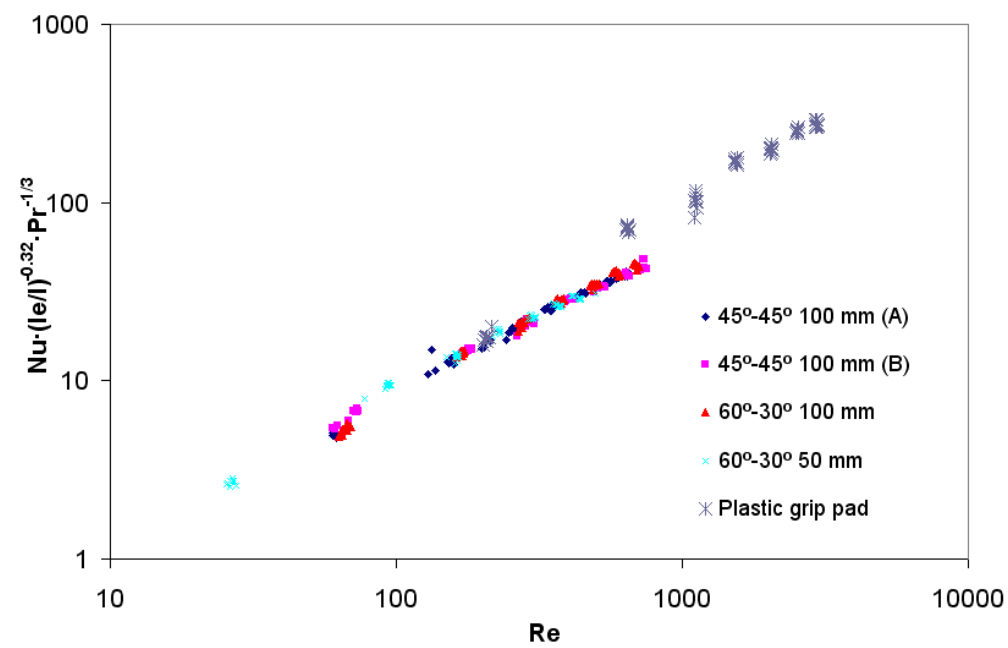

(a)

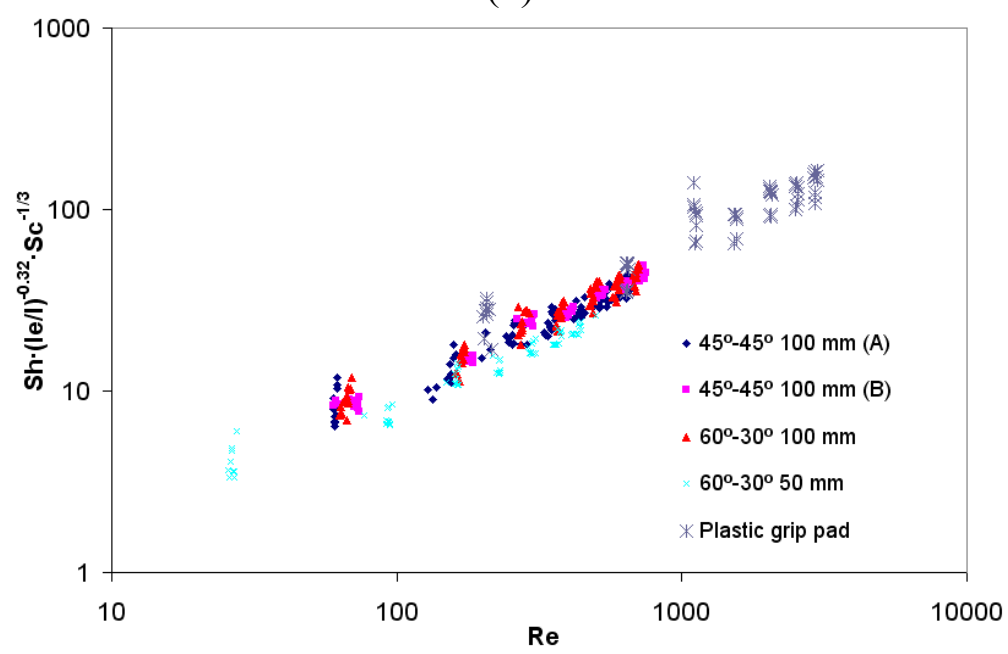

(b)

Assuming that heat and mass transfer occur at similar airflow rates, they give rise to an analogy among these processes, dividing Equation (11) by Equation (12) provides us with an analogous expression for the cellulose evaporative pads:

$$
\begin{gathered}
\frac{h_{\mathrm{H}}}{h_{\mathrm{M}}}=1.3762 \rho_{\mathrm{a}} C_{\mathrm{pa}} L_{\mathrm{e}}^{2 / 3} \\
R^{2}=0.8938
\end{gathered}
$$

where Le is the Lewis number $(\mathrm{Le}=\alpha / \mathrm{D})$.

\subsection{Evaporated Water}

Figure 12 compares the specific water consumption of the five evaporative materials studied at different air and water flows. The plastic grid block has the lowest consumption of water at air velocities of over $0.5 \mathrm{~m} \cdot \mathrm{s}^{-1}$, as at this value it presents the greatest saturation efficiency, and therefore the greatest reduction in air temperature. 
Figure 12. Comparison of the specific water consumption of the cellulose pads and the plastic grid block at different air velocities and water flows.

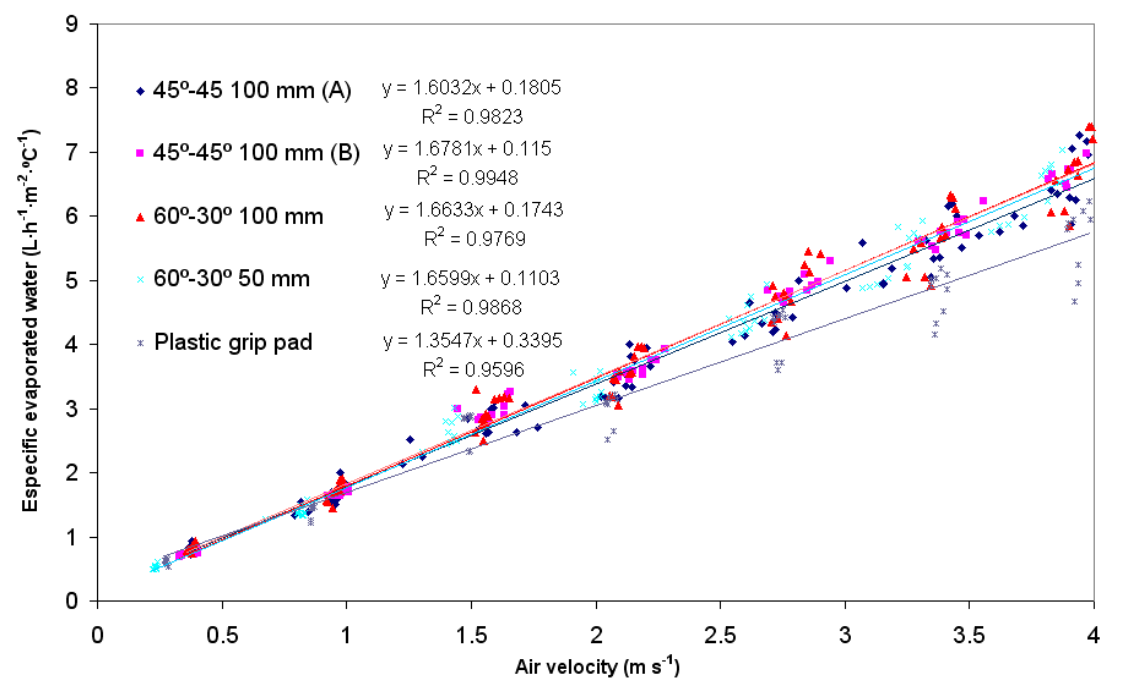

At air velocities of over $0.5 \mathrm{~m} \cdot \mathrm{s}^{-1}$, the difference between the specific water consumption of the plastic grid block and that of the cellulose pad with least consumption $\left(45^{\circ}-45^{\circ} 100 \mathrm{~mm}, \mathrm{~A}\right.$ pad) ranges between 0.03 and $0.83 \mathrm{~L} \cdot \mathrm{h}^{-1} \cdot \mathrm{m}^{-2} \cdot{ }^{\circ} \mathrm{C}^{-1}$, which represents a mean reduction of $10.81 \%$. In comparison with the cellulose pad with the highest consumption $\left(60^{\circ}-30^{\circ} 100 \mathrm{~mm}\right)$ the differences are greater, varying between 0.07 and $1.07 \mathrm{~L} \cdot \mathrm{h}^{-1} \cdot \mathrm{m}^{-2} \cdot{ }^{\circ} \mathrm{C}^{-1}$, i.e., a mean reduction of $14.52 \%$.

The pads' specific consumption of water is an important parameter due to the scarcity of this natural resource. This parameter allows us to design the components of the cooling system appropriately. The amount of water that is evaporated by the pad is related to the temperature and relative humidity of the outside air, the speed of the air flow through the pad, and to the geometry of the pads (thickness, specific contact area, angles of incidence, etc.).

\section{Conclusions}

The metal frames used to support the different types of evaporative pads during the wind tunnel experiments have been sown to be suitable for this purpose, as have the data measurement and recording devices, which proved highly versatile and easy to handle. This work has obtained both adimensional and empirical correlations which characterise the functioning of the different commercial models of cellulose and plastic evaporative materials tested, all of which presented different geometric characteristics. The correlations also characterise the air and water flows which pass through the pads.

Regarding the cellulose pads, as the water flow increases, so does the pressure drop produced by the pad, since the volume of water circulating over the pad increases and therefore the porosity and volume of air that can pass through the pad decrease. As for the plastic grid block, this increase in pressure drop is only noticeable when comparing values when the material is dry and when moist. No significant increase in pressure drop was registered as the water flow increased. For all materials tested the water flow has less influence on pressure drop than the airflow. Comparison of the resistance to the passage of air through the tested materials reveals that the plastic grid block produces the lowest pressure drop at all air and water flow rates. Indeed this material produces $51.27 \%$ less pressure drop 
than the best of the cellulose pads in this respect $\left(45^{\circ}-45^{\circ} 100 \mathrm{~mm}, \mathrm{~B}\right)$, and $94.87 \%$ less than the worst one $\left(45^{\circ}-45^{\circ} 100 \mathrm{~mm}, \mathrm{~A}\right)$.

It was also observed that when the water flow supplied to the pads was in excess of the amount that is evaporated, the airflow is the only factor that influences the following parameters: heat and mass transfer coefficients, air saturation efficiency and water consumption.

The plastic grid block produces the highest air saturation efficiency, with $82.63 \%$ at the lowest flow rate assayed $\left(0.171 \mathrm{~L} \cdot \mathrm{s}^{-1} \cdot \mathrm{m}^{-2}\right)$ and an air velocity of $2 \mathrm{~m} \cdot \mathrm{s}^{-1}$. Increasing the flow does not improve the air saturation efficiency. The four cellulose pads produce maximum values of air saturation efficiency of between $71 \%$ and $69 \%$ at low air velocities close to $0.5 \mathrm{~m} \cdot \mathrm{s}^{-1}$, and this efficiency decreases as the air velocity increases. However, increasing the water flow does not affect this parameter.

The specific water consumption of the materials, also termed the flow of evaporated water $\left(1 \mathrm{~h}^{-1}\right)$ per unit of contact surface $\left(\mathrm{m}^{2}\right)$ and ${ }^{\circ} \mathrm{C}$ which is able to reduce the temperature $\left(T_{1}-T_{2}\right)$ is directly proportional to the air velocity: the greater the air velocity, the greater the specific water consumption. On the other hand, it is inversely proportional to the materials' saturation efficiency: the greater the efficiency, the lower the specific water consumption.

For the cellulose pads, at air velocities of between 1 and $1.5 \mathrm{~m} \cdot \mathrm{s}^{-1}$ (ASABE recommend an air velocity of $1.27 \mathrm{~m} \cdot \mathrm{s}^{-1}$ for $100 \mathrm{~mm}$ pads [20]) the pressure drop ranges between 3.9 and $11.25 \mathrm{~Pa}$, depending on the type of pad and the water flow applied. The saturation efficiency is between 70 and $64 \%$, while the water consumption ranges from 1.8 to $2.62 \mathrm{~L} \cdot \mathrm{h}^{-1} \cdot \mathrm{m}^{-2} \cdot{ }^{\circ} \mathrm{C}^{-1}$.

Regarding the plastic grid block, at an air velocity of $2 \mathrm{~m} \mathrm{~s}^{-1}$, at which the maximum saturation efficiency occurs, the pressure drop is $11.05 \mathrm{~Pa}$ irrespective of the water flow, the mean saturation efficiency is $82.50 \%$ and the specific water consumption is $3.05 \mathrm{~L} \cdot \mathrm{h}^{-1} \cdot \mathrm{m}^{-2} \cdot{ }^{\circ} \mathrm{C}^{-1}$.

It would be beneficial for growers to be able to regulate the incoming air velocity. This would allow them to adapt to the requirements for air renewal in the greenhouse. This could be achieved by fitting frequency modulators to the extractor fans, and it would allow a considerable saving of energy in cooling the greenhouse.

\section{Acknowledgments}

This work has been financed by the Junta de Andalucía and the Ministerio de Ciencia e Innovación by means of the research grants P09-AGR-4593 and AGL2010-22284-C03-01, respectively.

\section{Conflicts of Interest}

The authors declare no conflict of interest.

\section{References}

1. Aznar, J.A.; Galdeano, E.; Álvarez, J.; Tapia, J.J.; Godoy, A. El Sector de la Comercialización Hortícola en Almería. Concentración, Prospectiva y Logística. In The Horticultural Marketing Sector in Almería. Concentration, Foresight and Logistics; Cajamar Caja Rural: Almería, Spain, 2013. (in Spanish) 
2. Montero, J.I. Evaporative cooling in greenhouses: Effect on microclimate, water use efficiency, and plant response. Acta Hortic. 2006, 719, 373-384.

3. Sethi, V.P.; Sharma, S.K. Survey of cooling technologies for worldwide agricultural greenhouse applications. Sol. Energy 2007, 81, 1447-1459.

4. Katsoulas, N.; Savas, D.; Tsirogiannis, I.; Merkouris, O.; Kittas, C. Response of an eggplant crop grown under Mediterranean summer conditions to greenhouse fog cooling. Sci. Hortic. 2009, 123, 90-98.

5. Sethi, V.P.; Sharma, S.K. Experimental and economic study of a greenhouse thermal control system using aquifer water. Energy Convers. Manag. 2007, 48, 306-319.

6. López, A.; Valera, D.L.; Molina-Aiz, F.D.; Peña, A. Sonic anemometry to evaluate airflow characteristics and temperature distribution in empty Mediterranean greenhouses equipped with pad-fan and fog systems. Biosyst. Eng. 2012, 113, 334-350.

7. Molina-Aiz, F.D.; Valera, D.L.; Álvarez, A.J. Measurement and simulation of climate inside Almería-type greenhouses using computational fluid dynamics. Agric. For. Meteorol. 2004, 125, $33-51$.

8. Valera, D.L.; Molina-Aiz, F.D. Evolución tecnológica de los invernaderos. (Technological evolution of the greenhouses). Phytoma 2008, 199, 47-52.

9. Franco, A.; Valera, D.L.; Peña, A.; Pérez, A.M. Aerodynamic analysis and CFD simulation of several cellulose evaporative cooling pads used in Mediterranean greenhouses. Comput. Electron. Agric. 2011, 76, 218-230.

10. Jain, J.K.; Hindoliya, D.A. Experimental performance of new evaporative cooling pad materials. Sustain. Cities Soc. 2011, 1, 252-256.

11. Ahmed, E.M.; Abaas, O.; Ahmed, M.; Ismail, M.R. Performance evaluation of three different types of local evaporative cooling pads in greenhouses in Sudan. Saudi J. Biol. Sci. 2011, 18, $45-51$.

12. Rawangkul, R.; Khedari, J.; Hirunlabh, J.; Zeghmati, B. Performance analysis of a new sustainable evaporative cooling pad made from coconut coir. Int. J. Sustain. Eng. 2008, 1, 117-131.

13. Gunhan, T.; Demir, V.; Yagcioglu, A.K. Evaluation of the suitability of some local materials as cooling pads. Biosyst. Eng. 2007, 96, 369-377.

14. Farmahini-Farahani, M.; Delfani, S.; Esmaeelian, J. Exergy analysis of evaporative cooling to select the optimum system in diverse climates. Energy 2012, 40, 250-257.

15. Lychnos, G.; Davies, P.A. Modelling and experimental verification of a solar-powered liquid desiccant cooling system for greenhouse food production in hot climates. Energy 2012, 40, 116-130.

16. Valera, D.L.; Álvarez, A.J.; Molina, F.D. Aerodynamic analysis of several insect-proof screens used in greenhouses. Span. J. Agric. Res. 2006, 4, 273-279.

17. Franco, A.; Valera, D.L.; Madueño, A.; Peña, A. Influence of water and air flow on the performance of cellulose evaporative cooling pads used in Mediterranean greenhouses. Trans. ASABE 2010, 3 , 565-576.

18. Das, R.S.; Jain, S. Experimental performance of indirect air-liquid membrane contactors for liquid desiccant cooling systems. Energy 2013, 57, 319-325. 
19. Franco, A. Contribución al Conocimiento de la Refrigeración Evaporativa: Paneles Evaporadores y Nuevas Aplicaciones Mediante Jardines Verticales Activos. (Contribution to the Knowledge of Evaporative Cooling: Evaporative Pad and New Applications Using Active Living Walls). Ph.D. Thesis, University of Almería, Almería, Spain, 24 July 2012. (in Spanish)

20. ANSI/ASABE Standards. EP406.4: Heating, Ventilating and Cooling Greenhouses; ASABE: St. Joseph, MI, USA, 2008.

21. Dowdy, J.A.; Karabash, N.S. Experimental determination of heat and mass transfer coefficients in rigid impregnated cellulose evaporative media. ASHRAE Trans. 1987, 93, 382-395.

22. Liao, C.M.; Chiu, K.H. Wind tunnel modeling the system performance of alternative evaporative cooling pads in Taiwan region. Build. Environ. 2002, 37, 177-187.

23. Incropera, F.P.; DeWitt, D.P. Fundamentos de Transferencia de Calor, 4th ed.; Prentice Hall: Upper Saddle River, NJ, USA, 1999. (in Spanish)

(C) 2014 by the authors; licensee MDPI, Basel, Switzerland. This article is an open access article distributed under the terms and conditions of the Creative Commons Attribution license (http://creativecommons.org/licenses/by/3.0/). 